\title{
Effect of Environmental Conditions on the NADP-Specific Glutamic Acid Dehydrogenase in Neurospora crassa
}

\author{
By R. W. BARRATT \\ The Department of Biological Sciences, Dartmouth College, and the Department \\ of Microbiology, Dartmouth Medical School, Hanover, \\ New Hampshire, U.S.A.
}

(Received 1 February 1963)

\section{SUMMARY}

The chemical form and quantity of nitrogen supplied during the growth of wild-type Neurospora crassa mycelia had a significant effect on total protein synthesis and NADP-specific glutamate dehydrogenase (NADP-GD) specific activity. Both NADP-GD specific activity and protein yields were high when $\mathrm{NH}_{4}{ }^{+}$was the sole nitrogen source. At $\mathrm{NH}_{4}{ }^{+}$concentrations up to the optimal for protein synthesis, NADP-GD production and protein synthesis were proportional; at higher concentrations NADP-GD specific activity decreased disproportionately. Glutamate alone, more markedly glutamate $+\mathrm{NH}_{4}{ }^{+}$, or a mixture of amino acids (e.g. sodium caseinate), similarly depressed NADP-GD specific activity. These data support the contention that excess nitrogen in some form acts as a specific NADP-GD repressor. Evidence is presented from experiments with nitrogen-starved mycelia that low concentrations of $\mathrm{NH}_{4}^{+}$per se may act to de-repress NADP-GD production. Under conditions of early nitrogen starvation, followed by a short growth period after $\mathrm{NH}_{4}^{+}$ supplementation, more than $1 \%$ of the soluble protein in a heat-treated extract was found to be NADP-GD.

\section{INTRODUCTION}

In Neurospora significant modification of enzyme production in response to environmental changes has been demonstrated in only a few instances (Fincham \& Boulter, 1956; Horowitz, Fling, MacLeod \& Watanabe, 1961; Yura \& Vogel, 1959; Kinsky, 1961; Turian, 1961 ; Lester, 1961). In contrast, the formation of inducible enzymes in bacteria has been found in nearly every case investigated. It is not known whether this apparent discrepancy between filamentous fungi and bacteria reflects fundamental differences in regulatory metabolic mechanisms or methodological difficulties in studying enzyme regulation in the filamentous fungi. Fincham (1962) and Barratt (1961) have reported the purification from mycelia of Neurospora crassa of a NADP-specific glutamate dehydrogenase (NADP-GD). Nicholas \& Mabey (1960) reported the occurrence of a glutamate dehydrogenase (GD) from Neurospora which utilizes either diphosphopyridine nucleotide (NAD) or triphosphopyridine nucleotide (NADP) as a coenzyme. Recently two glutamate dehydrogenases, one specific for NAD and the other specific for NADP, have been isolated (Sanwal \& Lata, $1961 a, b$ ), and these authors have reported effects of environmental conditions on the concurrent regulation of these two enzymes in Neurospora. 
The present paper reports the effects of certain environmental conditions on NADP-GD production and specific activity in Neurospora. Specifically, the effects of different nitrogen sources and the time of nitrogen supplementation are reported.

\section{METHODS}

Organisms. The following strains of Neurospora crassa were used: wild-typesSTA 4 (an asexual derivative of St Lawrence 74 A), I A, SY 7 A, SY 4 A. All these strains were obtained from the Fungal Genetics Stock Center, Dartmouth College, Hanover, New Hampshire, U.S.A.

Chemicals. $\alpha$-Ketoglutaric acid and reduced triphosphopyridine nucleotide $\left(\mathrm{NADPH}_{2}\right)$ were obtained from Sigma Chemical Company, St Louis, Missouri, U.S.A. (95\% pure; type I), the amino acids from the California Corporation for Biochemical Research, Los Angeles, California, U.S.A. and sodium caseinate from Nutritional Biochemical Corporation, Cleveland, Ohio, U.S.A.

Assay of NADP-GD. Assays were carried out by following the oxidation of reduced triphosphopyridine nucleotide $\left(\mathrm{NADPH}_{2}\right)$ in a quartz spectrophotometer cell of $1 \mathrm{~cm}$. light path in a Beckman Model DU or a Cary Model 14 spectrophotometer at $340 \mathrm{~m} \mu$ at room temperature. To a $4 \mathrm{ml}$. cell were added: $2 \cdot 1 \mathrm{ml}$. 0.2 $\mathrm{M}-2$ amino-2-hydroxymethylpropane-1,3-diol (tris) buffer (pH 7.8);0.2 ml. 0.167 $\mathrm{M}-\alpha$ -

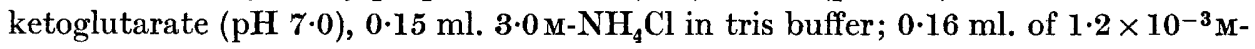
$\mathrm{NADPH}_{2}$ in tris buffer $(0 \cdot 16 \mathrm{ml}$. was sufficient to give a change in optical density (OD) of $0 \cdot 4$ ). The reaction was initiated by the addition of $0.1 \mathrm{ml}$. of enzyme solution. Enzyme concentrations were kept sufficiently low to give a linear reaction curve from 0 to 6 min.; in general one unit or less of NADP-GD was used in each assay. When crude enzyme preparations were used the reaction was initiated with $\alpha$ ketoglutarate and non-specific $\mathrm{NADPH}_{2}$ oxidation was subtracted from the rate obtained. In most experiments heat-treated fractions were used; these did not show any $\mathrm{NADPH}_{2}$ oxidation before substrate addition. A unit of enzyme activity was defined as the change in optical density at $E_{340}$ of $0.02 / \mathrm{min}$. Based on data to be published elsewhere, pure NADP-GD has a specific activity of about 25,000 units/ mg. protein when assayed at $25^{\circ}$.

Protein determinations. Protein determinations were made on the soluble proteins by using the Folin phenol method of Lowry, Rosebrough, Farr \& Randall (1951). Specific activity is expressed as units of enzyme activity/mg. protein.

Culture media. Four types of basal media were used: Fries medium (Beadle \& Tatum, 1945); medium N (Vogel \& Bonner, 1956); the basal nitrogen-free medium of Fincham (1954) supplemented with trace elements (Westergaard \& Mitchell, 1947) and designated as medium $F$ in the present paper; Wainwright's medium for producing conidia (Wainwright, 1959) supplemented with the above trace elements and designated as medium $W$ in the present paper. The carbon source of medium W was modified by replacing one half of the sucrose with glycerol (i.e. final concentration $1 \%(\mathrm{v} / \mathrm{v})$ glycerol).

Preparation of large batches of conidia. Maximal NADP-GD specific activity occurs shortly after conidial germination. Therefore to obtain significant quantities of protein, large conidial inocula became essential. Conidia were grown according to the method of Wainwright (1959) with the following modifications. Inoculated 
Fernbach flasks, containing $250 \mathrm{ml}$. modified medium $\mathrm{W}$, were incubated at $34^{\circ}$ in an upright position for $\mathbf{2 4} \mathrm{hr}$., then inverted and incubated for a second $\mathbf{2 4} \mathrm{hr}$. period. To induce maximal conidiation the flasks were transferred to room temperature in the light, inverted and aerated with a gentle stream of sterile humidified air for 3-4 days (about half the time necessary for maximal conidiation reported by Wainwright, 1959). Conidia were harvested in a $0 \cdot 1 \%(\mathrm{v} / \mathrm{v})$ sterile Tween 80 solution, loosened with a sterile nylon test-tube brush, filtered through a double layer of sterile gauze to remove mycelial fragments, centrifuged at $3000 \mathrm{~g}$ for $10 \mathrm{~min}$., and resuspended in sterile water. This procedure routinely yielded from each flask 3 to $6 \times 10^{10}$ conidia wet weight about $3 \cdot 2 \mathrm{~g}$. (dried by vacuum suction on Whatman no. 4 filter paper).

Conditions for growth. All mycelia used in these experiments were grown in aerated submerged cultures. No difference in total NADP-GD activity or specific activity was observed as between aeration on a shaker and this submerged forced aeration.

Preparation of extracts. Mycelia were harvested by vacuum filtration through S. and S. Sharkskin (Carl Schleicher and Schuell Company, Keene, New Hampshire, U.S.A.) filter paper, washed with distilled water and phosphate buffer $(0 \cdot 1 \mathrm{M}$; $\mathrm{pH} 7 \cdot 0$ ), frozen and stored. Frozen mycelium was ground in a Waring blender in cold $0 \cdot 1 \mathrm{M}$-phosphate buffer (pH 7.0) until uniformly homogenized, then transferred to a Virtis ' 45' homogenizer (The Virtis Company, Inc., Yonkers, New York, U.S.A.) and homogenized at full speed for $20 \mathrm{~min}$. in an ice bath. Routinely, the final homogenate was heated at $53^{\circ}$ for $30 \mathrm{~min}$., cooled, centrifuged at $12,000 \mathrm{~g}$ and the supernatant fluid assayed.

\section{RESULTS}

\section{Effect of chemical form of nitrogen}

In vivo in Neurospora, NADP-GD functions in the reductive amination of $\alpha$-keto acids since $a m$ strains, known to be deficient in NADP-GD do not grow in absence of transaminable $\alpha$-amino nitrogen (up to 3 days; Fincham, 1950). Consequently, the chemical form of nitrogen supplied might be expected to exert a regulatory effect. Neurospora mycelia were grown in media containing the following nitrogen sources: $(a) \mathrm{NH}_{4}{ }^{+}$; $(b)$ one half $\mathrm{NH}_{4}{ }^{+}$and one half $\mathrm{NO}_{3}{ }^{-}$(standard minimal medium $\mathrm{N})$; (c) readily transaminable $\alpha$-amino nitrogen; $(d)$ amino nitrogen not transaminable. The specific NADP-GD activities found under these growth conditions are given in Table 1. Twenty-five-fold differences in specific activity and total NADP-GD production were observed, but not under the same experimental conditions. Both NADP-GD-specific activity and protein yields were high when nitrogen was supplied as $\mathrm{NH}_{4}{ }^{+}$. Specific activity was the highest but growth and protein synthesis were minimal when the nitrogen was supplied in a poorly available form, e.g. glycine, serine, lysine (which Neurospora cannot transaminate; Fincham, 1951). The mycelia from these three flasks were pooled. Protein synthesis was high but specific NADP-GD activity was very low when nitrogen was supplied as a mixture of readily available amino acids (e.g. sodium caseinate). When $\alpha$-amino nitrogen was supplied as glutamate, protein synthesis was limited, NADP-GDspecific activity was high and increased with decreasing glutamate concentrations. Glutamate or some derived metabolite is a repressor of NADP-GD. However, 
other amino acids or their derived metabolites can also act as repressors, since hydrolysed casein decreases NADP-GD production much below that caused by a comparable concentration of glutamate. When one half of $\mathrm{NH}_{4}+$ was replaced by nitrate ion (standard medium $\mathbf{N}$ ) protein synthesis and specific activity were low.

Table 1. Effect of nitrogen source

Neurospora mycelium grown in $50 \mathrm{ml}$. culture medium containing $2 \%(\mathrm{w} / \mathrm{v})$ sucrose for $46 \mathrm{hr}$. at $33^{\circ}$ on rotary shaker. Inoculum: 6 drops of unfiltered conidial suspension of Neurospora strain sta 4. Assays on non-heat treated mycelial extracts.

Molarity (M) is expressed in terms of nitrogen.

$\begin{array}{cc}\text { Type } & \begin{array}{c}\text { Final } \\ \text { pH }\end{array} \\ \text { F* } & 3 \cdot 8 \\ \text { F } & 4 \cdot 0 \\ \text { F } & 4 \cdot 5 \\ \text { F } & 6 \cdot 2 \\ \text { F } & 6 \cdot 1 \\ \text { F } & 6 \cdot 3 \\ \text { F } & 5 \cdot 6 \\ \text { F } & 5 \cdot 6 \\ \text { F } & 5 \cdot 3 \\ \text { F } & 5 \cdot 3 \\ \text { N } & 5 \cdot 2\end{array}$

Compound
Ammonium tartrate
Ammonium tartrate
Ammonium tartrate
Glutamate
Glutamate
Glutamate
Sodium caseinate
Glycine
Serine
Lysine
None

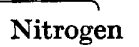

(M)

$0 \cdot 032$

0.065

$\mathbf{0} \cdot \mathbf{2 6 0}$

0.012

0.025

$0 \cdot 100$

$0.086 \ddagger$

0.050
0.037

$0 \cdot 140\}$

$0 \cdot 050 \mid$

$\begin{array}{cc}\begin{array}{c}\text { NADP-GD } \\ \text { protal } \\ \text { (mg.) }\end{array} & \begin{array}{c}\text { specific } \\ \text { activity } \\ \text { (u./mg.) }\end{array} \\ \mathbf{3 5 \cdot 0} & 139 \\ 25 \cdot 5 & 172 \\ 21 \cdot 5 & 9 \\ 7 \cdot 4 & 167 \\ 6 \cdot 2 & 121 \\ 9 \cdot 6 & 109 \\ 25 \cdot 2 & 20 \\ 5 \cdot 2 \S & 242 \\ 8 \cdot 2 & 45\end{array}$

* Initial $\mathrm{pH}$ value of medium $\mathrm{F}=\mathrm{pH} 5 \cdot 65$.

$\dagger$ Neutralized to $\mathrm{pH}$ 5.0 with $\mathrm{NaOH}$.

\$ Assumes molecular weight of sodium caseinate to be 150 and nitrogen content to be $16 \%$.

$\S$ For the three flasks.

$\|$ Medium $\mathrm{N}$ contain nitrogen as $0.025 \mathrm{M}-\mathrm{NH}_{4}{ }^{+}$and $0.025 \mathrm{M}-\mathrm{NO}_{3}{ }^{-}$.

\section{Effect of ammonium ion concentration}

As described above, the different concentrations of $\mathrm{NH}_{4}{ }^{+}$, supplied as $\mathrm{NH}_{4}$ tartrate, resulted in very different specific activities. Therefore, the regulatory effect of different concentrations of $\mathrm{NH}_{4}{ }^{+}$was investigated. A thirty-eight-fold difference in total activity, a fourfold difference in total protein and nearly a tenfold difference in specific activity was found over the range of nitrogen concentrations tested (Fig. 1). These marked differences were not accompanied by similar differences in the wet weight yields of mycelium. The optimal concentration of $\mathrm{NH}_{4}{ }^{+}$was $0.065 \mathrm{M}$ with respect to nitrogen for highest NADP-GD-specific activity and production. These results are consistent with a regulatory effect of $\mathrm{NH}_{4}{ }^{+}$on NADP-GD yield.

\section{Post-growth nitrogen starvation and its reversal}

Ammonium ions exert a regulatory effect: a low $\mathrm{NH}_{4}{ }^{+}$concentration results in high protein and NADP-GD-specific activity. Since any further decrease of $\mathrm{NH}_{4}{ }^{+}$ concentration markedly limited growth, post-growth nitrogen starvation might provide similar conditions of extreme $\mathrm{NH}_{4}{ }^{+}$limitation. Two-day mycelia were washed in phosphate buffer, transferred to nitrogen-free medium $\mathbf{F}$ and incubated for a further 2 days. The total NADP-GD production and specific activity doubled (Table 2). However, when the nitrogen starvation was prolonged for 6 days, the specific activity remained high but general protein catabolism occurred. More 

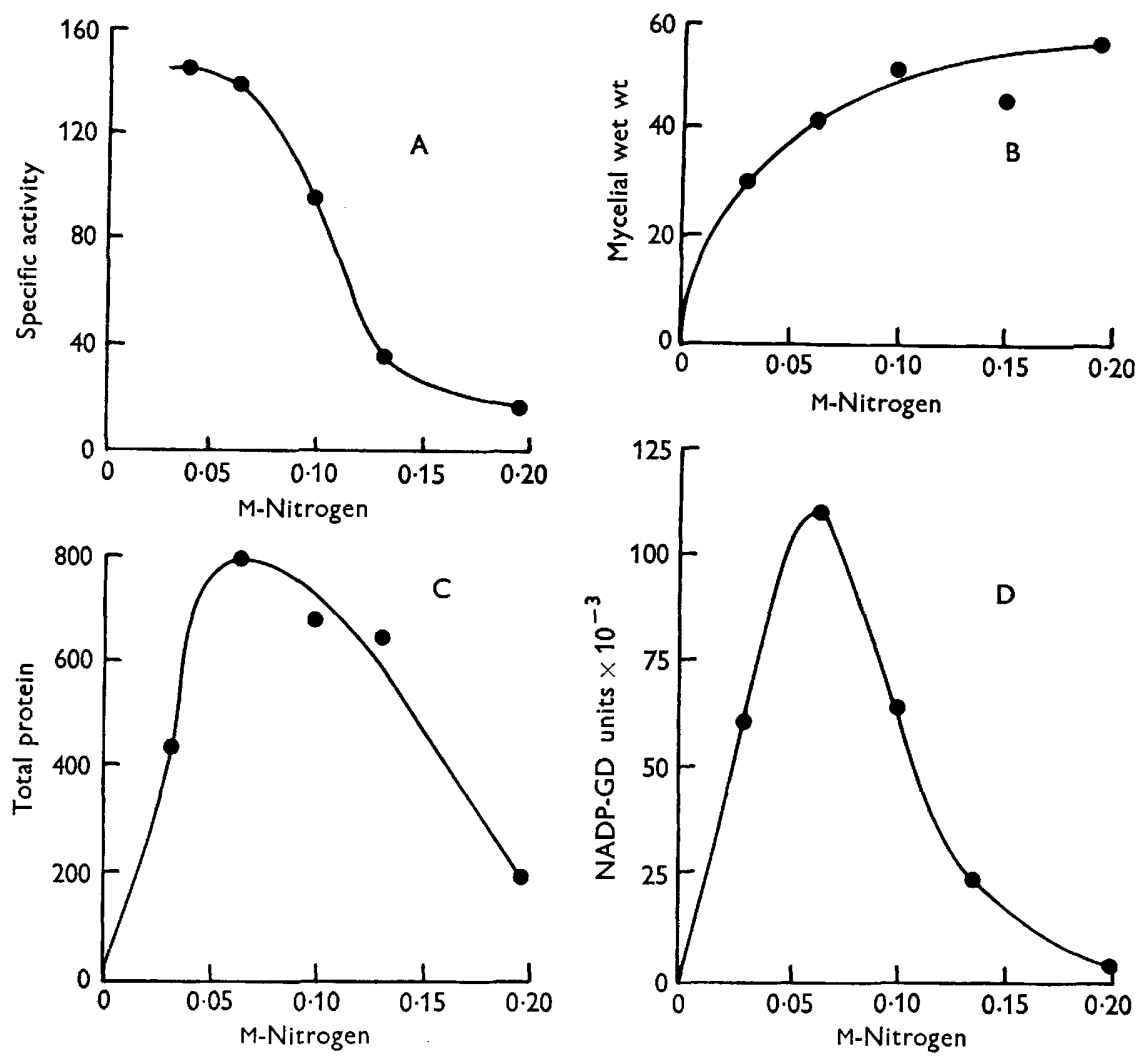

Fig. 1. The relationship between $\mathrm{NH}_{4}+$ concentration and mycelial growth of Neurospora, protein synthesis, NADP-GD synthesis, and NADP-GD-specific activity. Growth conditions : 1.6 l. medium F containing $2 \%(\mathrm{w} / \mathrm{v})$ sucrose and $5 \mu \mathrm{g}$. biotin/l.; forced aeration at $33^{\circ}$; inoculum, a conidial suspension of strain sTA 4 ; incubation period $48 \mathrm{hr}$. Protein determinations and NADP-GD assays made on non-heat treated extracts. $\mathrm{NH}_{4}{ }^{+}$concentration expressed as molarity of nitrogen. A, NADP-GD specific activity expressed as units/mg. protein; B, mycelial weight expressed as g. wet weight; C, protein expressed as total mg.; D, NADP-GD expressed as total units $+10^{-3}$.

\section{Table 2. Effect of post-growth nitrogen starvation and reversal with $\mathrm{NH}_{4}{ }^{+}$}

Neurospora mycelium grown in $50 \mathrm{ml}$. medium $\mathrm{N}^{*}$ containing $2 \%(\mathrm{w} / \mathrm{v})$ sucrose. Mycelium incubated for $48 \mathrm{hr}$. at $33^{\circ}$ on rotary shaker followed by treatment indicated below. Inoculum: filtered conidial suspension of strain sTa4. Assays on non-heat treated mycelial extracts.

\section{Treatment}

None (control)

Nitrogen starved for 2 days

Nitrogen starved for 6 days

Nitrogen starved for 6 days, then supplemented with $\mathrm{NH}_{4}$ tartrate, $\uparrow$ harvested after $6 \mathrm{hr}$.

$\begin{array}{lcc}\text { Growth } & \text { Total } & \text { Specific } \\ \text { period } & \text { protein } & \text { activity } \\ \text { (days) } & \text { (mg.) } & \text { (u./mg.) }\end{array}$

$\begin{array}{lrr}2 & 8 \cdot 2 & 45 \\ 4 & 7 \cdot 6 & 100 \\ 8 & 3 \cdot 3 & 115 \\ 8 \cdot 25 & 11 \cdot 8 & 159\end{array}$

* Final pH of culture media $5 \cdot 0$ to $5 \cdot 2$. Medium $\mathrm{N}$ is $0 \cdot 050 \mathrm{M}$ with respect to nitrogen. $\dagger$ Concentration brought to $0 \cdot 13 \mathrm{~m}$-nitrogen with ammonium tartrate. 
significantly, when 6-day nitrogen-starved mycelium was supplemented with $\mathrm{NH}_{4}$ tartrate to $0.13 \mathrm{M}$-nitrogen and allowed to grow for a further $6 \mathrm{hr}$., a nearly fourfold increase in total protein and an additional $50 \%$ increase in specific activity was found.

Concurrent variation in concentration of ammonium ion and time of growth

As shown above, NADP-GD production was markedly altered by $\mathrm{NH}_{4}{ }^{+}$concentration or post-growth nitrogen starvation. The effect of the two concentrations of $\mathrm{NH}_{4}+$ for two different periods of growth was investigated. Two flasks of medium $\mathrm{F}$, one supplemented with $0.016 \mathrm{M}$-nitrogen and the other with $0.065 \mathrm{M}$-nitrogen (both as $\mathrm{NH}_{4}$ tartrate), were inoculated with a very heavy conidial suspension (final concentration of $4 \times 10^{7}$ conidia/ml. culture medium). After incubation for $18 \mathrm{hr}$. one half of the mycelium from one flask of each concentration was harvested and the remainder harvested after incubation for $24 \mathrm{hr}$. At either concentration of nitrogen the specific activities were higher at $18 \mathrm{hr}$. than at $24 \mathrm{hr}$. (Table 3), but the differ-

Table 3. Effect of various concentrations of $\mathrm{NH}_{4}{ }^{+}$and growth period

Neurospora mycelium grown in 21 . medium $\mathrm{F}$ containing $2 \%(\mathrm{w} / \mathrm{v})$ sucrose $+5 \mu \mathrm{g}$. biotin/l. Aerated by bubbling at $\mathbf{3 3}^{\circ}$. Inoculum $8 \times 10^{10}$ conidia, strain sta 4. Data corrected for differences in volumes harvested. Assays on non-heat treated mycelial extracts.

\begin{tabular}{|c|c|c|c|}
\hline $\begin{array}{l}\text { Nitrogen } \\
\text { (ammonium } \\
\text { tartrate) } \\
\text { (M) }\end{array}$ & $\begin{array}{c}\text { Growth } \\
\text { period } \\
\text { (hr.) }\end{array}$ & $\begin{array}{l}\text { Total } \\
\text { protein } \\
\text { (mg.) }\end{array}$ & $\begin{array}{l}\text { NADP-GD } \\
\text { specific } \\
\text { activity } \\
\text { (u./mg.) }\end{array}$ \\
\hline 0.065 & 18 & $458 \cdot 0$ & $216 \cdot 0$ \\
\hline 0.016 & 18 & $365 \cdot 0$ & $222 \cdot 0$ \\
\hline 0.065 & 24 & $380 \cdot 0$ & $181 \cdot 0$ \\
\hline 0.016 & 24 & $297 \cdot 0$ & $139 \cdot 0$ \\
\hline
\end{tabular}

Table 4. Effect of time of harvest under conditions of early nitrogen starvation

Neurospora mycelium grown in 11 . medium $\mathrm{F}$ containing $2 \%(\mathrm{w} / \mathrm{v})$ sucrose $+5 \mu \mathrm{g}$. biotin/l. Aerated on shaker at $33^{\circ}$. Inoculum $1.4 \times 10^{10}$ conidia strain sTA 4 . No nitrogen supplied for $16 \mathrm{hr}$. Nitrogen supplemented to $0.065 \mathrm{M}$ with ammonium tartrate.

\begin{tabular}{|c|c|c|}
\hline $\begin{array}{c}\text { Growth } \\
\text { period } \\
\text { after } \\
\text { supple- } \\
\text { mentation } \\
\text { (hr.) }\end{array}$ & $\begin{array}{c}\text { Total } \\
\text { protein } \\
\text { (mg.) }\end{array}$ & $\begin{array}{l}\text { NADP-GD } \\
\text { specific } \\
\text { activity } \\
\text { (u./mg.) }\end{array}$ \\
\hline 10 & 218 & 301 \\
\hline 18 & $\mathbf{5 5 4}$ & 193 \\
\hline
\end{tabular}

ence was more marked at the lower nitrogen concentration. Addition of optimal nitrogen (to $0.065 \mathrm{M}$ ) after $18 \mathrm{hr}$. growth was without effect. Inconsistencies exist between the data from the two different nitrogen starvation experiments. The mycelium which was nitrogen starved for 6 days showed a marked response in NADP-GD and protein synthesis within $6 \mathrm{hr}$. after nitrogen supplementation (Table 2). In contrast, mycelium grown for $18 \mathrm{hr}$. on limited nitrogen, followed by growth for $6 \mathrm{hr}$. on adequate nitrogen, showed no increase in NADP-GD or protein 
synthesis. An experiment was therefore made in which nitrogen starvation preceded growth. Nitrogen-free medium $F$ was inoculated with a heavy suspension of conidia, with reliance for conidial germination on endogenous nitrogen reserves. After incubation for $16 \mathrm{hr}$. the medium was supplemented with $\mathrm{NH}_{4}$ tartrate to the optimal concentration (equiv. 0.065 M-nitrogen; see Fig. 1), the mycelium incubated for a further 10-18 hr. and harvested (Table 4). Microscopic examination of the inoculated media just before supplementation showed that most conidia had germinated but that mycelial growth was insignificant. When nitrogen was supplied and incubation was only for $10 \mathrm{hr}$., the specific activity was the highest obtained in any experiment. When incubation was for $18 \mathrm{hr}$., the total units of NADP-GD almost doubled and the total protein increased almost $2 \cdot 5$-fold. These data support the idea of early NADP-GD synthesis in relation to total protein synthesis and confirm the marked stimulatory effect of $\mathrm{NH}_{4}{ }^{+}$on nitrogen-starved mycelia.

\section{Effect of carbon source}

Since ammonium ion has a marked regulatory effect on NADP-GD activity, variations in the other substrate $\alpha$-ketoglutarate might also exert regulatory effects. Because of the instability of $\alpha$-keto acids at the $\mathrm{pH}$ value of the culture medium used, no direct test seemed feasible. One indirect approach would be to attempt regulation of the concentration of tricarboxylic acid cycle intermediates by altering the concentration of carbohydrate. Different concentrations of sucrose showed maximal NADP-GD activity at $1 \%(\mathrm{w} / \mathrm{v})$, the lowest concentration used (Table 5). When the sucrose concentration was only $0 \cdot 1 \%$ there was very poor mycelial growth and low NADP-GD yields. Neurospora cannot use glutamate as sole carbon source, so that a direct test of end-product repression was not possible.

\section{Table 5. Effect of sucrose concentration under conditions of early nitrogen starvation}

Neurospora mycelium grown in 11 . medium $\mathrm{F}$ containing $5 \mu \mathrm{g}$. biotin/l. Aerated on shaker at $33^{\circ}$. Inoculum $1.4 \times 10^{10}$ conidia strain sta4. No nitrogen supplied for $16 \mathrm{hr}$. Nitrogen supplemented to $0.065 \mathrm{M}$ with ammonium tartrate. Incubation $18 \mathrm{hr}$. after supplementation.

$\begin{array}{ccc}\begin{array}{c}\text { Sucrose } \\ (\%, w / v)\end{array} & \begin{array}{c}\text { Total } \\ \text { protein } \\ (\mathrm{mg})\end{array} & \begin{array}{c}\text { Specific } \\ \text { activity } \\ (\mathrm{u} . / \mathrm{mg} .)\end{array} \\ \mathbf{1 . 0} & \mathbf{4 5 4} & \mathbf{2 7 4} \\ \mathbf{2 . 0} & 554 & 193 \\ 5.0 & 512 & 150\end{array}$

\section{Inhibitory effect of glutamate}

Fincham (1954) and Sanwal \& Lata $(1962 a, b)$ showed repression of NADP-GD by glutamate in the presence of $\mathrm{NH}_{4}{ }^{+}$. Similar experiments have now been made with four wild-type strains. In all cases glutamate in a molar ratio of $\mathbf{0} \cdot 25$ with respect to total nitrogen repressed NADP-GD formation. The repression observed was qualitatively but not quantitatively in agreement with the recent findings of Sanwal \& Lata $(1962 a, b)$ in which glutamate was used in a molar ratio 0.50 with respect to total nitrogen. 


\section{DISCUSSION}

During growth of Neurospora wild-type mycelia, total protein and NADP-GD synthesis was markedly influenced by the chemical form in which nitrogen was supplied. Of the nitrogen source investigated highest NADP-GD-specific activity and protein synthesis were consistently obtained when $\mathrm{NH}_{4}{ }^{+}$was the nitrogen source. Since NADP-GD catalyses the reductive amination of $\alpha$-keto acids in Neurospora (Fincham, 1950), correlation under these conditions between high protein synthesis and high NADP-GD production is not unexpected. However: glutamate, the product of the synthetic activity of the enzyme, is not a sufficient single source of nitrogen for high protein synthesis even when supplied at three times the nitrogen concentration of $\mathrm{NH}_{4}{ }^{+}$. At concentrations of $\mathrm{NH}_{4}{ }^{+}$up to the optimal for protein synthesis, NADP-GD and protein synthesis increased in parallel, i.e. the specific activity remained constant. Above the optimal value NADP-GDspecific activity decreased sevenfold with a fourfold increase in $\mathrm{NH}_{4}{ }^{+}$, and with no effect on mycelial growth. A repressing effect of $\mathrm{NH}_{4}{ }^{+}$or some compound in the nitrogen pool seems indicated.

Similarly, the depressing effect of glutamate alone, glutamate $+\mathrm{NH}_{4}{ }^{+}$or a mixture of amino acids, on specific activity support the contention that excess nitrogen in some form acts as a repressor. Sanwal \& Lata $(1962 b)$ concluded that urea is the repressor of NADP-GD. However, their data differ from those reported here in that they found that replacement of urea with equivalent amounts of $\mathrm{NH}_{4}{ }^{+}$(presumably 0.24 M with respect to nitrogen) had no significant effect on specific activity. Data reported here show a $90 \%$ decrease in specific activity when $0.195 \mathrm{M}$-nitrogen was used instead of 0.065 M-nitrogen (as $\mathrm{NH}_{4}$ tartrate; see Fig. 1). Thus these data do not indicate urea as the repressor. Evidence reported by Sanwal \& $\operatorname{Lata}^{r}(1962 b)$ on the substitution of alanine, ornithine, or valine for the repressing effect of glutamate in the presence of $\mathrm{NH}_{4}{ }^{+}$is conflicting. High alanine, ornithine, and valine transaminase activities have been reported in Neurospora in the presence of the respective specific substrates (Fincham \& Boulter, 1956); yet Sanwal \& Lata (1962b) found that alanine and ornithine but not valine substituted in reproducing the glutamate depression effect. An understanding of the mechanism of $\mathrm{NH}_{4}{ }^{+}$repression awaits the application of short-time induction experiments in which the environment remains relatively constant during the experiment, such as those with washed mycelia recently reported in studies with nitrate reductase regulation in Neurospora (Kinsky, 1961).

Ammonium ion per se may actually act to de-repress NADP-GD production. Specific activity is low in conidia and increases nearly eightfold within the first $24 \mathrm{hr}$. of incubation (nitrogen supplied as a mixture of $\mathrm{NH}_{4}{ }^{+}$and $\mathrm{NO}_{3}{ }^{-}$(Sanwal \& Lata, $1962 a$ ). Extreme restriction of $\mathrm{NH}_{4}{ }^{+}$by growth of mycelium in presence of glycine, serine and lysine results in poor growth but high specific NADP-GD activity. When severely nitrogen-starved mycelium is supplemented with $\mathbf{N H}_{4}{ }^{+}$, a rapid reversal of soluble protein and NADP-GD catabolism is observed, as well as an increase in specific activity. Conidia germinated in nitrogen-free media and then supplemented with $\mathrm{NH}_{4}{ }^{+}$yielded mycelium with the highest NADP-GD specific activity observed under any experimental conditions, and decreasing with time. Because of the unique role of this enzyme in the incorporation of $\mathbf{N H}_{4}{ }^{+}$into 
$\alpha$-amino nitrogen, complicated by regeneration of $\alpha$-aminoglutarate via transaminations, the regulatory mechanism of induction and repression of NADP-GD may be complex and elusive.

To obtain maximal total NADP-GD synthesis, the concentration of $\mathrm{NH}_{4}{ }^{+}$and nitrogen starvation appear to be significant. The highest NADP-GD yields accompanied by high specific activity were obtained under conditions in which nitrogenstarved mycelium, germinating on endogenous reserves, was harvested $10 \mathrm{hr}$. after supplementation with $\mathrm{NH}_{4}{ }^{+}$. Under these conditions more than $1 \%$ of the soluble protein in heat-treated fractions was found to be NADP-GD. While NADP-GD synthesis continued after $10 \mathrm{hr}$. the total protein synthesis occurred more rapidly, resulting in a lower specific activity.

The author wishes to acknowledge support of the U.S. National Science Foundation Grant G-8985. Some of the work was done while the author was a special postdoctoral Fellow of the U.S. National Institutes of Health, and working in the laboratory of Dr C. Yanofsky (Department of Biological Sciences, Stanford University).

\section{REFERENCES}

BARRATt, R. W. (1961). Studies on gene-protein relations with glutamic dehydrogenase in Neurospora crassa. Rec. Genet. Soc. Amer. 31, 59.

Beadle, G. W. \& Tatum, E. L. (1945). Neurospora. II. Methods of producing and detecting mutations concerned with nutritional requirements. Amer. J. Bot. 32, 678.

Fincham, J. R. S. (1950). Mutant strains of Neurospora deficient in aminating ability. J. biol. Chem. 182, 61.

Fincham, J. R. S. (1951). Transaminases in Neurospora crassa. Nature, Lond. 168, 957.

Fincham, J. R. S. (1954). Effects of a gene mutation in Neurospora crassa relating to glutamic dehydrogenase formation. J. gen. Microbiol. 11. 236.

Fincham, J. R. S. (1962). Genetically determined multiple forms of glutamic dehydrogenase in Neurospora crassa. J. mol. Biol. 4, 257.

Fincham, J. R. S. \& Boulter, D. G. (1956). Effects of amino acids on transaminase production in Neurospora crassa: evidence for four different enzymes. Biochem. J. 62, 72.

Horowitz, N. H., Fling, M., MacLeod, H. L. \& Watanabe, Y. (1961). Structural and regulative genes controlling tyrosinase synthesis in Neurospora. Cold Spr. Harb. Symp. quant. Biol. 26, 233.

KINSKY, S. C. (1961). Induction and repression of nitrate reductase in Neurospora crassa. J. Bact. 82, 898.

LESTER, G. (1961). Indole synthesizing activity repressed by tryptophan. J. Bact. 82, 215.

Lowry, O. H., Rosebrough, N. J., Farr, A. L. \& Randall, R. J. (1951). Protein measurement with the Folin phenol reagent. J. biol. Chem. 193, 265.

Nicholas, D. J. D. \& MABEy, G. L. (1960). Some properties of glutamic dehydrogenase from Neurospora crassa. J. gen. Microbiol. 22, 184.

SANWAL, B. D. \& LATA, M. (1961 $a$ ). Glutamic dehydrogenase in single gene mutants of Neurospora deficient in amination. Nature, Lond. 190, 286.

Sanwal, B. D. \& LATA, M. (1961 b). The occurrence of two different glutamic acid dehydrogenases in Neurospora crassa. Canad. J. Microbiol. 7, 319.

Sanwal, B. D. \& Lata, M. (1962a). Effect of glutamic acid on the formation of two glutamic acid dehydrogenases of Neurospora. Biochem. biophys. Res. Comm. 6, 404.

Sanwal, B. D. \& Lata, M. (1962 b). Concurrent regulation of glutamic acid dehydrogenases of Neurospora. Arch. Biochem. Biophys. 97, 582.

Turian, G. (1961). L'acetate et son double effet d'induction isocitratasique et de differenciation conidienne chez les Neurospora. C.R. Acad. Sci., Paris, 252, 1374. 
Vogel, H. J. \& BonNer, D. M. (1956). A convenient growth medium for Neurospora. Microbiol. Genet. Bull. 13, 42.

WaInwright, S. D. (1959). On the development of increased tryptophan synthetase activity by cell free extracts of Neurospora crassa. Canad. J. Biochem. Physiol. 37, 1417.

WestergaArd, M. \& Mitchell, H. K. (1947). Neurospora V. A synthetic medium favouring sexual reproduction. Amer. J. Bot. 34, 573.

Yura, T. \& Vogel, H. J. (1959). Pyrroline-5-carboxylate reductase of Neurospora crassa: partial purification and some properties. J. biol. Chem. 234, 335. 